\title{
Predictors of Salvia divinorum Use Among a National Sample of Entering First-year U.S. College Students
}

\author{
Julie M. Croff ${ }^{1}$ and William DeJong ${ }^{2}$ \\ ${ }^{1}$ School of Applied Health and Educational Psychology, Oklahoma State University, Stillwater, OK, United States \\ ${ }^{2}$ Department of Community Health Sciences, Boston University School of Public Health, Boston, MA, United States
}

\begin{abstract}
Objective: Past epidemiological studies have revealed that 18- to 25-year-olds have the highest rate of Salvia divinorum (salvia) use. This study examines predictors of salvia use among a large national sample of incoming first-year college students attending 144 academic institutions.

Method: Each institution instructed their entering first-year students to complete an online alcohol course. A total of 7,314 randomly selected students completed a version of the course's baseline survey that included questions about salvia use.

Results: Salvia use in the past two weeks was reported by $3.5 \%$. In a multivariate model, past-two-week salvia use was more common among students who were male, non-White, and had an absent father; this study did not correct for multiple statistical tests, and therefore, these results may be spurious. Salvia use and use of cigarettes and marijuana were strongly related in bivariate analyses. Current drinkers were approximately two times more likely to use salvia in the past two weeks. More than a third of those reporting past-two-week salvia use reported using salvia while under the influence of marijuana in the past month.

Discussion: This study is the first to examine salvia and other substance use over the past two weeks and explores the use of salvia under the influence of marijuana. Students being disciplined for marijuana-related offenses should be questioned about the concomitant use of salvia.
\end{abstract}

Salvia divinorum (salvia) is a hallucinogenic herb in the mint family. The indigenous Mazatec of the Oaxaca region of Mexico used salvia as a medical treatment and to induce spiritual visions (Valdes, Hatheld, Koreeda, \& Paul, 1987). Traditional use involves chewing the leaves or brewing a tea in order to release Salvinorin A, the herb's active component (Valdes et al., 1987). In contrast, today dried salvia leaves are typically smoked, which can be purchased in a super-strength form boosted by tinctures of Salvinorin A.

Salvia smokers have reported inhaling a median of three times with each use, and each time holding in the smoke a median of 20 seconds before exhaling (Baggott, Erowid, Galloway, \& Mendelson, 2010). Hallucinogenic symptoms emerge in about 30 seconds, but typically last less than ten minutes (Lange et al., 2010). Emerging and young adults use hallucinogens at the highest rates (Chilcoat \& Schütz, 1996), and several studies have identified emerging and young adults as the most likely to use salvia. For example, one national study found that salvia use is highest among young adults ages $18-25$, males, Whites, and recent users of other drugs (Wu, Woody, Yang, Li, \& Blazer, 2011).

In the United States, legality of salvia varies by state; however, research indicates that its use is a global phenomenon (Casselman, Nock, Wohlmuth, Weatherby, \& Heinrich, 2014). The lifetime prevalence rate for salvia use in the United States was 1.3\% in 2008 (Wu et al., 2011) and between 2-5\% in 2009 (Ford, Watkins, \& Blumenstein, 2011; Perron et al., 2012). Some epidemiological reports suggest that salvia use may be a declining fad, yet usage rates among young adults appear to have remained constant over time. Monitoring the Future has reported that use is decreasing among U.S. adolescents (Johnston, O'Malley, Bachman, \& Schulenberg, 2011). The 2009 National Survey on Drug Use and Health indicated that lifetime salvia use was reported by just less than $2 \%$ of adolescents ages $12-17$ but $5 \%$ of young adults ages $18-34$ (Ford et al., 2011).

Lange, Reed, Croff, and Clapp conducted the first epidemiological study of salvia use among undergraduate

Correspondence: Julie M. Croff, School of Applied Health and Educational Psychology, Oklahoma State University, 429 Willard Hall, Stillwater, OK 74078, USA. Telephone: 405-744-1850, E-mail: Julie.croff@ okstate.edu

Financial support: No grant funds supported this project. The data presented here were provided through the online course AlcoholEdu for College by EverFi, Inc., Washington, DC.

Declaration of interest: The authors have no conflict of interest to declare.

Keywords: college, Salvia divinorum, substance use 
college students, focusing on a large public university in the southwestern United States. Past-year use was reported by $4.4 \%$ of the survey participants (2008). Being male and using other drugs in the past year remained significant predictors of salvia use after controlling for race/ethnicity, affiliation with a fraternity or sorority, and past-month alcohol use. Another early study reported $6.7 \%$ lifetime use among students attending another public university, but only $3.0 \%$ reported past-month use and $0.5 \%$ past-week use (Khey, Miller, \& Griffin, 2008). Significant predictors of use included race/ethnicity, socioeconomic status, and pastmonth use of marijuana.

Salvia prevalence rates diminish significantly from lifetime to past-month use, implying that most people who experiment with the drug do not transition to frequent or long-term use (Khey et al., 2008; Miller, Griffin III, Gibson, \& Khey, 2009). In one study, nearly one third of salvia users said they disliked the high, and nearly one third reported having lost interest in the drug (Nyi et al., 2010). In another study, more than half of college salvia users said that they would not use the drug again, while approximately one third said they would consider doing so and only about one in six said they would definitely use salvia again (Khey et al., 2008).

Nationally representative surveys have shown that other illicit drug use is the strongest predictor of salvia use $(\mathrm{Wu}$ et al., 2011). Marijuana users are 27 times more likely to use salvia than non-marijuana users (Perron et al., 2012). Other national studies have also shown a strong association between salvia use and other substance use (Johnston et al., 2011; Nyi et al., 2010). It is expected that over a ten-year period, approximately half of all salvia-related reports made to a statewide poison control system involved the concomitant use of illicit drugs (Vohra, Seefeld, Cantrell, \& Clark, 2011).

Salvia is commonly sold online and at neighborhood "head shops" where illicit drug paraphernalia may also be purchased. One study found that users identified head shops as their primary source of salvia (Sumnall, Measham, Brandt, \& Cole, 2011). Interestingly, just over one quarter of users reported using salvia as a legal alternative to illicit drugs, while $72.1 \%$ stated they would continue to use salvia even if it were made illegal (Sumnall et al., 2011).

Prior to the present investigation, no national study had examined correlates of salvia use among a large national sample of first-year college students. Incoming college students are at heightened risk for substance use upon arrival on campus (Del Boca, Darkes, Greenbaum, \& Goldman, 2004), which may negatively impact retention (Sullivan \& Risler, 2011; Wood, Sher, Erickson, \& DeBord, 1997). Determining the prevalence of salvia use among incoming college students may aid college administrators in development of substance-use prevention programming on campus.

Previous studies have examined salvia use over the past year and past month but not over the past two weeks. This study examines predictors of past-two-week salvia use among a sample of incoming first-year college students from 144 institutions of higher education who completed a baseline substance-use survey as part of an online alcohol education course taken annually by approximately one third of college freshmen entering a four-year institution.

\section{Method}

In 2010, a national sample of incoming first-year college students from 144 colleges and universities completed a baseline survey that was part of AlcoholEdu for College, an online alcohol course marketed by Outside The Classroom, Inc., now part of EverFi, Inc. Students included in these analyses were required to take the course prior to the first day of classes (pre-matriculation).

Students entered the course using the university's assigned login ID, and then used their university e-mail address to create a personal account. To maintain confidentiality, the account-creation process was protected using SSL encryption, and the students' personal information was dissociated from their survey responses. The dataset prepared for analysis had all individual identifiers removed. A total of 7,314 randomly selected incoming first-year students completed a version of the survey that included questions about salvia use. The sample was $42.4 \%$ male and $69.6 \%$ White. The vast majority of the respondents were 18 years of age $(76.3 \%)$ or older $(20.3 \%)$.

The Institutional Review Board at Oklahoma State University approved the secondary data analysis of the data set.

\section{Survey Items \\ Demographics}

Several demographic and socioeconomic questions were included in the pre-matriculation survey. These items included gender, race/ethnicity, age, plans to pledge a Greek-letter organization, and parental educational attainment. Father's presence in the student's life was recoded from a measure of paternal education, wherein not applicable responses were coded to indicate that the father was not present, and all other responses to indicate some level of involvement in the student's life.

\section{Substance use items}

Several items related to use of alcohol, tobacco, or other drugs were included in this survey. Age of first drink has been linked to alcohol use disorders (AUD) if before age 15 ; therefore, the question regarding age of first drink was coded categorically to represent risk of AUD. The survey also assessed past-two-week use of alcohol, cigarettes, marijuana, and several other illicit drugs, including salvia use. Use of salvia under the influence of alcohol and marijuana was also assessed; however, these questions were asked in the past-month time period. 


\section{Data Analysis}

For descriptive purposes, we calculated general frequencies for past-two-week use of Salvia divinorum, alcohol, and marijuana. Next, for both the demographic variables and other types of substance use, we conducted bivariate chisquare analyses to compare students who did versus did not use Salvia divinorum in the past two weeks. Mother's education was included as a proxy for parents' socioeconomic status and related parenting behaviors, as we anticipated that variables related to family environment could be an important predictor for previous drug-use behaviors among incoming freshmen.

Finally, we developed a multivariate logistic regression model that included key demographic variables and significant substance-use predictors of Salvia divinorum use.

\section{Results}

Alcohol use in the past two weeks was reported by more than a quarter $(28.7 \%)$ of the sample (Table 1). Cigarette and marijuana use in the past two weeks were each reported by approximately $3 \%$ and $3.2 \%$ of the sample, respectively (Table 1). In the past two weeks, 3.5\% $(n=256)$ of the study participants reported using Salvia divinorum (Table $1)$.

Chi-square analyses were used to examine the relationship between previous two-week salvia use and several demographic and substance-use variables (Table 1). These bivariate analyses suggested significant relationships between recent use of salvia and sex, race/ethnicity, and father's presence. Current age, intention to join a Greekletter organization, and mother's educational status were not significantly related to past-two-week salvia use. Drinking initiation before age 15 and alcohol, cigarette, and marijuana use in the past two weeks were also significantly associated with past-two-week salvia use (Table 1). Specifically, students who had used salvia in the past two weeks were more likely to 1) be male, 2) identify as a race/ethnicity other than White, 3) have an absent father, 4) have been under the age of 15 when he/she first drank alcohol, and 5) have used alcohol, cigarettes, and marijuana in the past two weeks (Table 1).

Given the strength of the association between past-twoweek marijuana use and the reported use of salvia, one exploratory hypothesis is that salvia use may co-occur with marijuana use. Of participants reporting past 2-week salvia use $(n=256), 34.3 \%(n=88)$ reported using salvia under the influence of marijuana in the past month.

The final logistic regression analysis is presented in Table 2. Only variables with significant bivariate analyses were included in the initial model. The reduced full model included sex, race/ethnicity, having an absent father, and past-two-week alcohol use. Past-two-week cigarette and marijuana use were not included in the initial or final logistic regression models due to concerns with collinearity with salvia use (Pearson correlations .965 and $.967, p \leq$ 0.01 , respectively). Notably, males, students with absent fathers, and current drinkers were nearly twice as likely to have used salvia in the past two weeks.

Table 1

Past-two-week use of Salvia divinorum by risk factor

\begin{tabular}{|c|c|c|c|c|c|}
\hline \multirow{3}{*}{ Su } & Sample & $\begin{array}{c}\text { No Salvia Use in } \\
\text { Past } 2 \text { Weeks } \\
\end{array}$ & $\begin{array}{l}\text { Salvia Use in } \\
\text { Past } 2 \text { Weeks } \\
\end{array}$ & \multirow[b]{2}{*}{$\chi^{2}$} & \multirow[b]{2}{*}{$p$ value } \\
\hline & Total \% (n) & Row \% (n) & Row \% (n) & & \\
\hline & & & & & \multirow[b]{3}{*}{$p \leq .001$} \\
\hline Male & $42.4 \%(3101)$ & $95.4 \%$ (2959) & $4.6 \% \quad(142)$ & \multirow[b]{2}{*}{18.56} & \\
\hline Female & $57.6 \%(4213)$ & $97.3 \%(4099)$ & $2.7 \% \quad(114)$ & & \\
\hline \multicolumn{6}{|l|}{ Race/Ethnicity } \\
\hline White & $69.6 \%(5089)$ & $96.9 \%(4929)$ & $3.1 \% \quad(160)$ & \multirow{2}{*}{6.28} & \multirow{2}{*}{$p=.012$} \\
\hline Other & $30.4 \%(2225)$ & $95.7 \%(2129)$ & $4.3 \% \quad(96)$ & & \\
\hline \multicolumn{6}{|l|}{ Age } \\
\hline$\leq 18$ & $79.7 \% \quad(5827)$ & $96.6 \% \quad(5627)$ & $(200)$ & \multirow{2}{*}{0.39} & \multirow{2}{*}{$p=.53$} \\
\hline$>19$ & $20.3 \%(1487)$ & $96.2 \%(1431)$ & $3.8 \% \quad(56)$ & & \\
\hline \multicolumn{6}{|l|}{ Father's Status } \\
\hline Not Present & $4.1 \% \quad(296)$ & $92.6 \% \quad(274)$ & $7.4 \% \quad(22)$ & \multirow{2}{*}{14.01} & \multirow{2}{*}{$p \leq .001$} \\
\hline Present & $95.9 \% \quad(6997)$ & $96.7 \% \quad(6763)$ & $3.3 \% \quad(234)$ & & \\
\hline \multicolumn{6}{|c|}{ Mother's Educational Status } \\
\hline $\mathrm{N} / \mathrm{A}^{\mathrm{a}}$ & $2.0 \% \quad(107)$ & $96.3 \% \quad(103)$ & $3.7 \%$ & & \\
\hline Some High School & $2.5 \% \quad(137)$ & $98.5 \% \quad(135)$ & $1.5 \%$ & & \\
\hline High School & $15.4 \%(829)$ & $96.6 \%(801)$ & $3.4 \% \quad(28)$ & & \\
\hline Some College & $17.0 \%(915)$ & $97.7 \%(894)$ & $2.3 \% \quad(21)$ & 4.28 & $p=.64$ \\
\hline Technical School & $3.3 \% \quad(180)$ & $96.7 \% \quad(174)$ & $3.3 \% \quad(6)$ & & \\
\hline College Graduate & $39.7 \%(2137)$ & $96.6 \%(2064)$ & $3.4 \% \quad(73)$ & & \\
\hline Graduate School & $20.1 \%(1082)$ & $96.9 \%(1048)$ & $3.1 \% \quad(34)$ & & \\
\hline
\end{tabular}




\begin{tabular}{|c|c|c|c|c|c|c|}
\hline \multicolumn{7}{|l|}{ Organization } \\
\hline Yes & $24.3 \%(1176)$ & $96.1 \%(1707)$ & $3.9 \%$ & (69) & \multirow{2}{*}{1.03} & \multirow{2}{*}{$p=.31$} \\
\hline No & $75.7 \%(5538)$ & $96.6 \%(5351)$ & $3.4 \%$ & $(187)$ & & \\
\hline \multicolumn{7}{|c|}{ Age of First Drink } \\
\hline$>15$ & $93.3 \%(6814)$ & $96.7 \%(6586)$ & $3.3 \%$ & (228) & \multirow{2}{*}{7.82} & \multirow{2}{*}{$p=.005$} \\
\hline$\leq 15$ & $6.7 \% \quad(486)$ & $94.2 \% \quad(458)$ & $5.8 \%$ & $(28)$ & & \\
\hline \multicolumn{7}{|c|}{ Alcohol Use in Past 2 Weeks } \\
\hline Used & $28.7 \%(2101)$ & $94.4 \%(1983)$ & $5.6 \%$ & $(118)$ & \multirow{2}{*}{39.09} & \multirow{2}{*}{$p \leq .001$} \\
\hline Abstained & $71.3 \%(5213)$ & $97.4 \%(5075)$ & $2.6 \%$ & (138) & & \\
\hline \multicolumn{7}{|c|}{ Cigarette Use in Past 2 Weeks } \\
\hline Used & $3.0 \%(220)$ & $3.6 \%(8)$ & $96.4 \%$ & $(212)$ & \multirow{2}{*}{5791.2} & \multirow{2}{*}{$p \leq .001$} \\
\hline Abstained & $97.0 \%(7094)$ & $99.4 \%(7050)$ & $0.6 \%$ & $(44)$ & & \\
\hline \multicolumn{7}{|c|}{ Marijuana Use in Past 2 Weeks } \\
\hline Used & $3.2 \%(236)$ & $3.8 \%(9)$ & $96.2 \%$ & $(227)$ & \multirow{2}{*}{6202.6} & \multirow{2}{*}{$p \leq .001$} \\
\hline Abstained & $96.8 \%(7078)$ & $99.6 \%(7049)$ & $0.4 \%$ & (29) & & \\
\hline
\end{tabular}

Table 2

Reduced multivariate logistic regression predictors of past-two-week use of Salvia divinorum

\begin{tabular}{lccc}
\hline & AOR & 95\% CI & $p$ value \\
\hline $\begin{array}{l}\text { Sex (with Female as referent group) } \\
\quad \text { Male }\end{array}$ & 1.93 & $0.38-0.70$ & $p \leq .001$ \\
$\begin{array}{l}\text { Race/Ethnicity (with Other as referent group) } \\
\quad \text { White }\end{array}$ & 0.72 & $0.51-1.0$ & $p=.05$ \\
$\begin{array}{l}\text { Father's Status (with Present as referent group) } \\
\quad \text { Not Present }\end{array}$ & 2.14 & $1.13-4.04$ & $p=.019$ \\
$\quad \begin{array}{l}\text { Alcohol Use in Past 2 Weeks (with Abstained as referent group) } \\
\quad \text { Used }\end{array}$ & 1.90 & $1.39-2.61$ & $p \leq .001$ \\
\hline
\end{tabular}

\section{Discussion}

As other studies have found (Khey et al., 2008; Khey, Stogner, \& Miller, 2014; Lange et al., 2008; Miller et al., 2009; Wu et al., 2011), this study affirmed that salvia use is more common among males. Salvia use peaks nationally with the 18-25 age group (Wu et al., 2011). This study sampled individuals on the front end of that age range. Therefore, consistent with findings from other studies of salvia users attending college (Lange et al., 2008), age did not predict past-two-week salvia use among this national sample of first-year college students.

A strong bivariate relationship was found between salvia use and the use of alcohol, cigarettes, and marijuana. More information is needed on the use of salvia while under the influence of alcohol. Although the link between salvia use and the use of alcohol and marijuana has been identified in other studies (Nyi et al., 2010; Perron et al., 2012; Wu et al., 2011), the present study is the first to reveal that salvia is often used under the influence of marijuana. Moreover, this study identifies a strong bivariate relationship between smoked substances in the past two weeks, indicating, perhaps, that some first-year college students have a preference for smoking as a mechanism of drug delivery. The relationship between tobacco, marijuana, and salvia use may be partly explained by a specific environmental link-namely, head shops, which Sumnall and colleagues identified as the most frequent purchase point for salvia (Sumnall et al., 2011). In states where salvia can be purchased legally, students may not consider it to be a harmful drug.

These findings have important implications for prevention work on campus. First, if students are being disciplined for alcohol- or marijuana-related offenses, school officials may also want to ask about the concomitant use of salvia, as well as other drugs. Second, to counter media publicity about salvia use, which often creates the false impression that the drug is frequently used by college students, prevention programs could include social-norms messages reporting the fact that only a minority of college students use this substance. While this is not specifically a recommendation for a social-norms campaign, evidence from Sanders, Stogner, and Miller found that college students overestimate novel drug use, including salvia (2013). The social nature of salvia use may make it a prime candidate for social-norms campaigns. Third, student health centers and other medical facilities serving college students need to ask about salvia use directly to avoid underreporting, in part because its hallucinogenic effects may have additional implications for students with poor mental health. Note that Lange and colleagues found that reporting of salvia use under an "other" category resulted in lower apparent prevalence rates (2008). 
This study is limited by the use of a convenience sample of first-year students. While this study randomly selected AlcoholEdu students to complete the salvia questions, the sample of participating colleges and universities was not randomly selected. The relationships found between salvia use and the predictive variables are valid and generalizable. Inconsistent with other studies that identified White race/ethnicity as a covariate (Baggott et al., 2010; Ford et al., 2011; Khey et al., 2008; Miller et al., 2009; Nyi et al., 2010), this study of entering first-year college students identified non-White race/ethnicity as a significant covariate of salvia use. This study did not correct for multiple statistical tests, and therefore, the results of these racial findings, and the findings associated with paternal presence, may be spurious. These findings warrant exploration in future studies.

This is the first study of salvia use that includes a national sample of college students. Results of this study mirror previous research on demographic predictors of salvia use, with the exception that this sample was the first in which non-White participants reported higher levels of use. Perhaps the use of the past-two-week time period rather than another time period contributed to the demographic discrepancy between the current report and previous studies. Moreover, this study is the first to examine salvia and other substance use over the past two weeks and explores the use of salvia under the influence of marijuana. Because this study focuses on use in the two-week period before students completed the survey, as opposed to the past month or year, the usage rates reported here are much lower than those that have been previously reported in studies conducted at individual universities (Khey et al., 2008; Khey et al., 2014; Lange et al., 2008; Miller et al., 2009). While this study and other research have focused on individual-level predictors of salvia use among college students, additional research is needed to gauge the impact of state-level policy.

\section{References}

Baggott, M. J., Erowid, E., Galloway, G. P., \& Mendelson, J. (2010). Use patterns and self-reported effects of Salvia divinorum: An internet-based survey. Drug and Alcohol Dependence, 111(3), 250-256.

Casselman, I., Nock, C. J., Wohlmuth, H., Weatherby, R. P., \& Heinrich, M. (2014). From local to global-Fifty years of research on Salvia divinorum. Journal of Ethnopharmacology, 151(2), 768-783.

Chilcoat, H. D., \& Schütz, C. G. (1996). Age-specific patterns of hallucinogen use in the US population: An analysis using generalized additive models. Drug and Alcohol Dependence, 43(3), 143-153.

Del Boca, F. K., Darkes, J., Greenbaum, P. E., \& Goldman, M. S. (2004). Up close and personal: Temporal variability in the drinking of individual college students during their first year. Journal of Consulting And Clinical Psychology, 72(2), 155-164.

Ford, J. A., Watkins, W. C., \& Blumenstein, L. (2011). Correlates of Salvia divinorum use in a national sample: Findings from the 2009 National Survey on
Drug Use and Health. Addictive Behaviors, 36(11), 1032-1037.

Johnston, L. D., O'Malley, P. M., Bachman, J. G., \& Schulenberg, J. E. (2011). Monitoring the Future national survey results on drug use, 1975-2010 (Volume I, Secondary School Students). Bethesda, Maryland: National Institute on Drug Abuse.

Khey, D. N., Miller, B. L., \& Griffin, O. H. (2008). Salvia divinorum use among a college student sample. Journal of Drug Education, 38(3), 297-306.

Khey, D. N., Stogner, J., \& Miller, B. L. (2014). Case studies of emerging drugs: Salvia, bath salts, and Bromo-DragonFly. In B. L. Miller \& J. M. Stonger (Eds.), Emerging trends in drug use and distribution: SpringerBriefs in criminology (pp. 53-73). New York, NY: Springer.

Lange, J. E., Daniel, J., Homer, K., Reed, M. B., \& Clapp, J. D. (2010). Salvia divinorum: Effects and use among YouTube users. Drug and Alcohol Dependence, 108(1), 138-140.

Lange, J. E., Reed, M. B., Croff, J. M. K., \& Clapp, J. D. (2008). College student use of Salvia divinorum. Drug and Alcohol Dependence, 94(1), 263-266.

Miller, B. L., Griffin III, O. H., Gibson, C. L., \& Khey, D. N. (2009). Trippin' on Sally D: Exploring predictors of Salvia divinorum experimentation. Journal of Criminal Justice, 37(4), 396-403.

Nyi, P. P., Lai, E. P., Lee, D. Y., Biglete, S. A., Torrecer, G. I., \& Anderson, I. B. (2010). Influence of age on Salvia divinorum use: Results of an Internet survey. Journal of Psychoactive Drugs, 42(3), 385-392.

Perron, B. E., Ahmedani, B. K., Vaughn, M. G., Glass, J. E., Abdon, A., \& Wu, L.-T. (2012). Use of salvia divinorum in a nationally representative sample. The American Journal of Drug and Alcohol Abuse, 38(1), 108-113.

Sanders, A., Stogner, J. M., \& Miller, B. L. (2013). Perception vs. reality: An investigation of the misperceptions concerning the extent of peer novel drug use. Journal of Drug Education, 43(2), 97-120.

Sullivan, M., \& Risler, E. (2011). Understanding college alcohol abuse and academic performance: Selecting appropriate intervention strategies. Journal of College Counseling, 5(2), 114-123.

Sumnall, H. R., Measham, F., Brandt, S. D., \& Cole, J. C. (2011). Salvia divinorum use and phenomenology: Results from an online survey. Journal of Psychopharmacology, 25(11), 1496-1507.

Valdes, L. J., Hatheld, G. M., Koreeda, M., \& Paul, A. G. (1987). Studies of Salvia divinorum (Lamiaceae), an hallucinogenic mint from the Sierra Mazateca in Oaxaca, Central Mexico. Economic Botany, 41(2), 283-291.

Vohra, R., Seefeld, A., Cantrell, F. L., \& Clark, R. F. (2011). Salvia divinorum: Exposures reported to a statewide poison control system over 10 years. The Journal of Emergency Medicine, 40(6), 643-650.

Wood, P. K., Sher, K. J., Erickson, D. J., \& DeBord, K. A. (1997). Predicting academic problems in college from freshman alcohol involvement. Journal Of Studies On Alcohol, 58(2), 200-210. 
Wu, L.-T., Woody, G. E., Yang, C., Li, J.-H., \& Blazer, D. G. (2011). Recent national trends in Salvia divinorum use and substance-use disorders among recent and former Salvia divinorum users compared with nonusers. Substance Abuse and Rehabilitation, 2, 5368. 